\title{
A PERFORMANCE STUDY ON PARTIAL REPLACEMENT OF POLYMER INDUSTRIES WASTE (PIW) AS FINE AGGREGATE IN CONCRETE
}

\author{
K.SRINIVASAN ${ }^{1}$, Dr.J.PREMALATHA ${ }^{2}$, S.SRIGEETHAA ${ }^{3}$
}

\begin{abstract}
Recycling of plastic wastes helps in reducing waste disposal problems and helps for the sustainable development of the country. Concrete with various \% (0 to 55\%) of waste plastic aggregates were tested for their mechanical strength properties. In the present work, plastic aggregates obtained as end product of a polymer recycle industry in the form of grains called as plastic aggregates are used as fine aggregate replacements in concrete. The addition of plastic aggregate as fine aggregate replacements results in increase in compressive strength, split tensile strength and flexural strength and thus helps in production of sustainable concrete. It is observed that, the optimum $\%$ of replacement of sand with waste plastic waste is $40 \%$ and it is also found that upto $55 \%$ of sand replacements with plastic wastes, mechanical strength values are comparable with that of the normal concrete.
\end{abstract}

Keywords: polymer industrial waste (PIW), Compressive strength, Split Tensile, Flexure Fine aggregate

\footnotetext{
${ }^{1}$ Assistant Professor., M.E., Gnanamani College of Technology, Faculty of Civil Engineering, Namakkal- 637018, Tamil Nadu, India, e-mail:salemvasan@gmail.com

${ }^{2}$ Head and Professor., M.E.,PhD., Kumaraguru College Of Technology, Faculty of Civil Engineering, Coimbatore641049, Tamil Nadu, India, e-mail:premravi_11@rediffmail.com

${ }^{3}$ Assistant Professor., M.E., Gnanamani College of Technology, Faculty of Civil Engineering, Namakkal- 637018, Tamil Nadu, India, e-mail:srigeethaa2009@gmail.com
} 


\section{INTRODUCTION}

As the world population grows, so do the amount and type of wastes being generated. Plastic is universally in today's existence. It is used for packaging, protecting, serving and even disposing of all kinds of consumer goods. With the industrial revolution, mass production of goods started and plastic seems to be a cheaper and effective raw material. Concrete plays an important role in the beneficial use of these materials in construction. Use of waste material in civil engineering has a huge scope as there are many means of fulfilling the quality standards lost due to waste usage. Using waste material reduces the load on environment as well as reduces cost of production. The wastage of plastic is increasing day by day, although steps were taken to reduce its consumption. India generates 6.5 million metric tons of plastic waste annually, of which 86 per cent was collected, and 33 per cent was treated and remaining 67 per cent disposed of at dump sites. So we took polymer industries waste for replace by sand in concrete. Plastic waste's effect can be reduced by reusing it in other sectors. PCPW are the waste end products obtained from the polymer industry. The wastes are brought up from the recycled plastic wastes from the polymer industry. The PCPW materials include in the waste PVC pipes, spirals Tests were conducted to determine the properties of PCPW aggregate such as density and specific gravity. The study focused on the use of plastic waste as fines aggregates resulting from the crushing of polymer industry waste rejected into nature and to find new ways of restraint in the field of construction.

\section{SCOPE AND OBJECTIVES}

Plastics have become an inseparable and integral part of human lives. Most of the plastic wastes are left as stockpiles, landfill material or illegally dumped in selected areas. The reuse of waste plastic materials in construction industry has been investigated through a large number of research works. The main objectives of the current research work is to design a concrete mix of grade M30 and study the influence of addition of plastic waste on the workability and mechanical strength such as compressive strength, tensile strength and flexural strength. 
A substantial growth in the consumption of plastic waste is observed all over the world in recent Years, which has led to huge quantities of unwanted plastic product waste. These wastes are non-biodegradable and will remain in a landfill without any degradation for a very long time and their accumulation may provoke fire or health hazards and cause troublesome environmental problem. Concrete is by far the most widely- used man made construction material and studies indicate that it will continue to be so in the years and decades to come. The advances in concrete have paved way for the reutilization of waste materials in concrete which help to prevent environmental pollution whilst contribution to the design of more economical building.

The use of plastic in concrete has become increasingly popular generating significant research interest over the past twenty years. Looking to the global issue of environmental pollution by plastic waste, research efforts have been focused on consuming this waste on massive scale in efficient and environmental friendly manner.

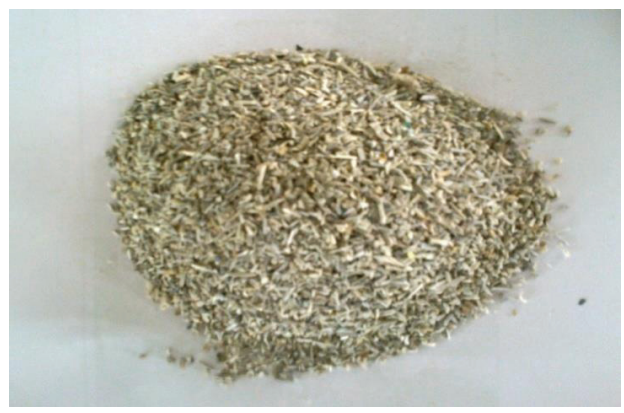

Fig.1.Polymer Industries Waste (PIW)

\section{METHODOLOGY}

Plastic waste are mostly collected are plastic toys, buckets, mug, mix body parts, grinder body parts which is reusable. Crushing the plastic waste into make powder form. Heat the plastic waste to attain melting point. Compress the material into hardened form using machine. Making smaller size plastic using machine into size suitable for fine aggregate.

\section{STRENGTH TESTS}

The concrete mix was designed for M30 concrete and various tests conducted on concrete specimens. This study involved 3 tests to determine the competence of reusing waste plastic in the 
production of concrete. Waste plastic was used as a partial replacement for sand by $0 \%, 5 \%, 10 \%$, $15 \%, 20 \%, 25 \%, 30 \%, 35 \%, 40 \%, 45 \%, 50 \%$ and $55 \%$ with concrete mixtures. These tests include performing slump, compressive strength, and split tensile strength.

For Compressive strength tests, concrete cubes of size $150 \mathrm{~mm} \times 150 \mathrm{~mm} \times 150 \mathrm{~mm}$ were used. Split tensile strength tests were conducted using cylindrical concrete specimens of diameter $150 \mathrm{~mm}$ and height $300 \mathrm{~mm} .108$ numbers of cubes were moulded for compressive strength, 108numbers of cylinders were cast for split tensile strength tests and 108 numbers of prisms were cast for flexural strength tests. For flexural strength $100 \mathrm{~mm}$ x $100 \mathrm{~mm}$ x $500 \mathrm{~mm}$ prism specimens were casted.

\section{RESULTS AND DISCUSSIONS}

The test results for various mechanical strength of hardened concrete with partial replacement of natural sand with plastic aggregates are given from Table 1 to Table 2 and from Figure 2 to Figure 6.11.

Table 1. Compressive strength of concrete with plastic waste aggregates

\begin{tabular}{|c|c|c|c|c|}
\hline \multicolumn{5}{|c|}{ Compressive strength (N/mm $)$} \\
\hline Sl. No & \% of plastic & 7 Days & 14 Days & 28 Days \\
\hline 1 & $0 \%$ & 16.83 & 29.53 & 36.74 \\
\hline 2 & $5 \%$ & 17.07 & 30.43 & 36.99 \\
\hline 3 & $10 \%$ & 17.93 & 24.56 & 37.63 \\
\hline 4 & $15 \%$ & 20.44 & 25.91 & 37.63 \\
\hline 5 & $20 \%$ & 21.47 & 29.25 & 38.73 \\
\hline 6 & $25 \%$ & 24.27 & 31.57 & 41.62 \\
\hline 7 & $30 \%$ & 23.95 & 33.41 & 42.62 \\
\hline 8 & $35 \%$ & 23.97 & 30.93 & 43.61 \\
\hline 9 & $40 \%$ & 20.41 & 27.49 & 38.18 \\
\hline 10 & $45 \%$ & 19.02 & 27.67 & 36.19 \\
\hline 11 & $50 \%$ & 13.3 & 27.23 & 32.8 \\
\hline 12 & $55 \%$ & 12.62 & 26.22 & 32.31 \\
\hline
\end{tabular}




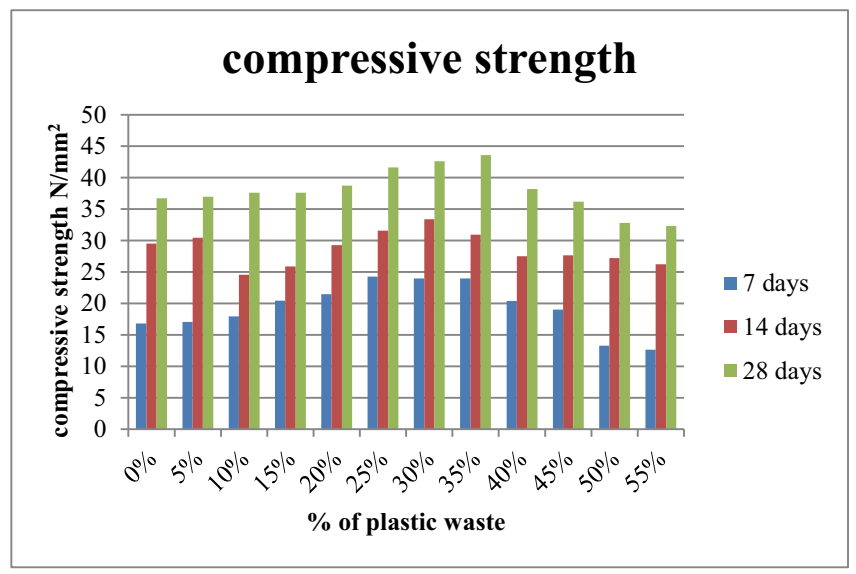

Fig. 2. Bar chart for Compressive strength of concrete with plastic waste aggregates

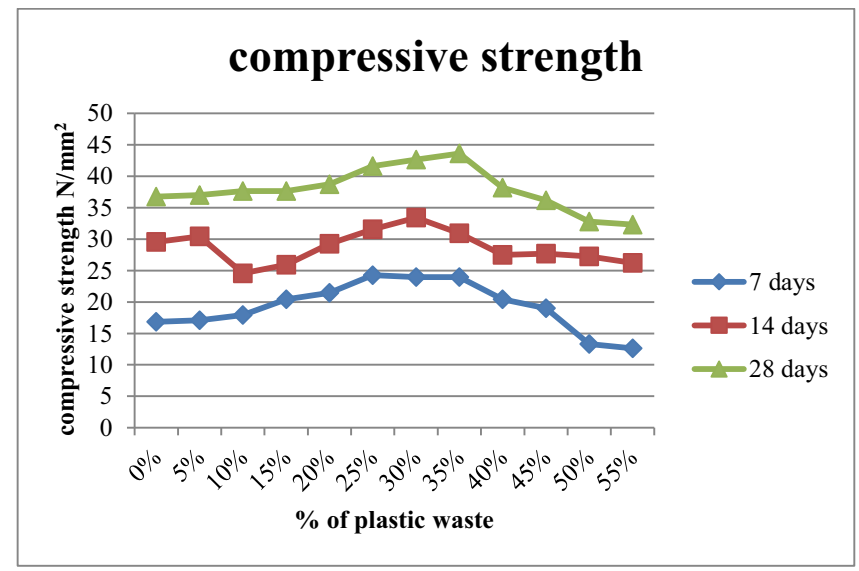

Fig. 3. Compressive strength of concrete with plastic waste aggregates at various ages 
Table 2. Split tensile strength of concrete with plastic waste aggregates

\begin{tabular}{|c|c|c|c|c|}
\hline \multicolumn{5}{|c|}{ Split tensile strength (N/mm $\left.{ }^{2}\right)$} \\
\hline SI.No & \% of plastic & $\mathbf{7 d a y s}$ & $\mathbf{1 4 d a y s}$ & $\mathbf{2 8 d a y s}$ \\
\hline 1 & $0 \%$ & 1.627 & 2.221 & 3.272 \\
\hline 2 & $5 \%$ & 1.697 & 2.23 & 3.05 \\
\hline 3 & $10 \%$ & 1.702 & 2.324 & 3.598 \\
\hline 4 & $15 \%$ & 1.753 & 2.357 & 3.648 \\
\hline 5 & $20 \%$ & 1.76 & 2.384 & 3.724 \\
\hline 6 & $25 \%$ & 1.782 & 2.408 & 3.867 \\
\hline 7 & $30 \%$ & 1.806 & 2.392 & 3.926 \\
\hline 8 & $35 \%$ & 1.794 & 2.361 & 3.958 \\
\hline 9 & $40 \%$ & 1.765 & 2.328 & 3.762 \\
\hline 10 & $45 \%$ & 1.729 & 2.253 & 3.412 \\
\hline 11 & $50 \%$ & 1.653 & 2.219 & 3.163 \\
\hline 12 & $55 \%$ & 1.608 & 2.134 & 3.076 \\
\hline
\end{tabular}

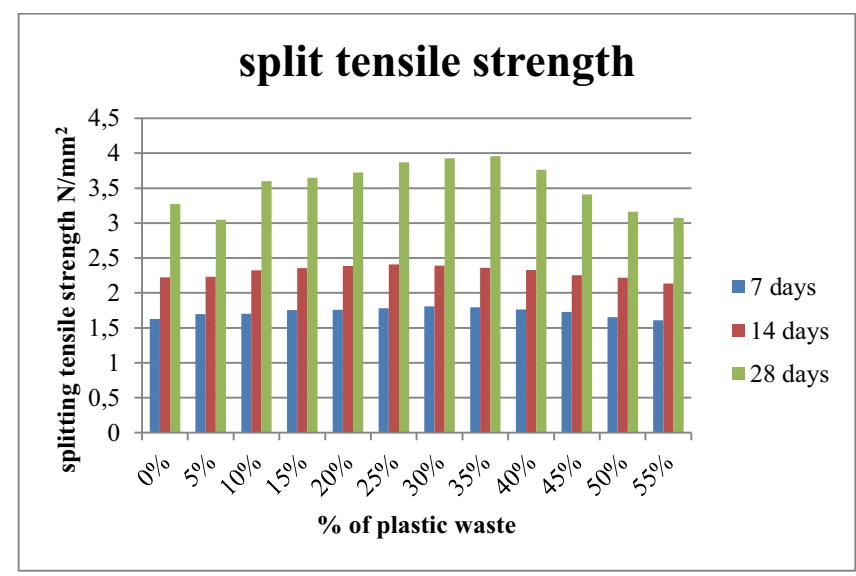

Fig. 4. Bar chart for Split tensile strength of concrete with plastic waste aggregates 


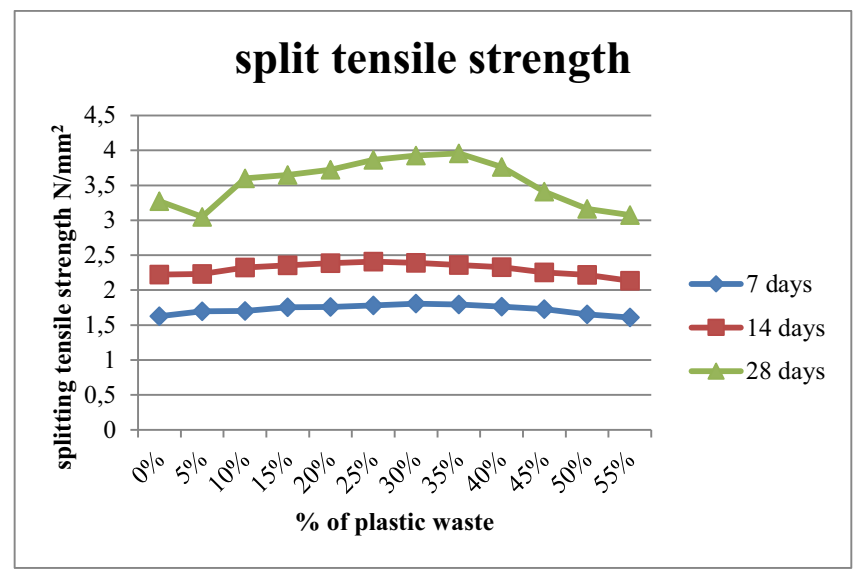

Fig. 5. Chart for Split tensile strength of concrete with plastic waste aggregates at various ages

Table 3. Flexural strength of concrete with plastic waste aggregates

\begin{tabular}{|c|c|c|c|c|}
\hline \multicolumn{5}{|c|}{ Flexural strength (N/mm $\left.{ }^{2}\right)$} \\
\hline Sl.No & \% of plastic & 7 days & 14days & 28days \\
\hline 1 & $0 \%$ & 2.42 & 3.05 & 4.36 \\
\hline 2 & $5 \%$ & 2.45 & 3.26 & 4.89 \\
\hline 3 & $10 \%$ & 2.67 & 3.84 & 5.34 \\
\hline 4 & $15 \%$ & 3.01 & 4.27 & 6.91 \\
\hline 5 & $20 \%$ & 3.54 & 5.46 & 7.23 \\
\hline 6 & $25 \%$ & 3.98 & 5.98 & 7.59 \\
\hline 7 & $30 \%$ & 4.52 & 6.48 & 7.92 \\
\hline 8 & $35 \%$ & 4.93 & 6.97 & 8.24 \\
\hline 9 & $40 \%$ & 4.28 & 6.23 & 7.66 \\
\hline 10 & $45 \%$ & 4.05 & 5.74 & 7.08 \\
\hline 11 & $50 \%$ & 3.67 & 5.12 & 6.76 \\
\hline 12 & $55 \%$ & 3.12 & 4.56 & 6.48 \\
\hline
\end{tabular}




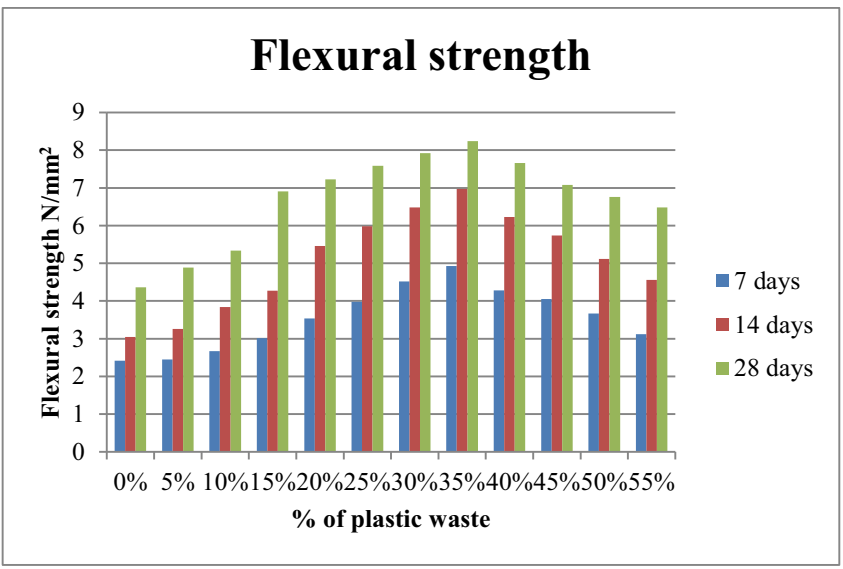

Fig. 6. Bar chart for Flexural strength of concrete with plastic waste aggregates

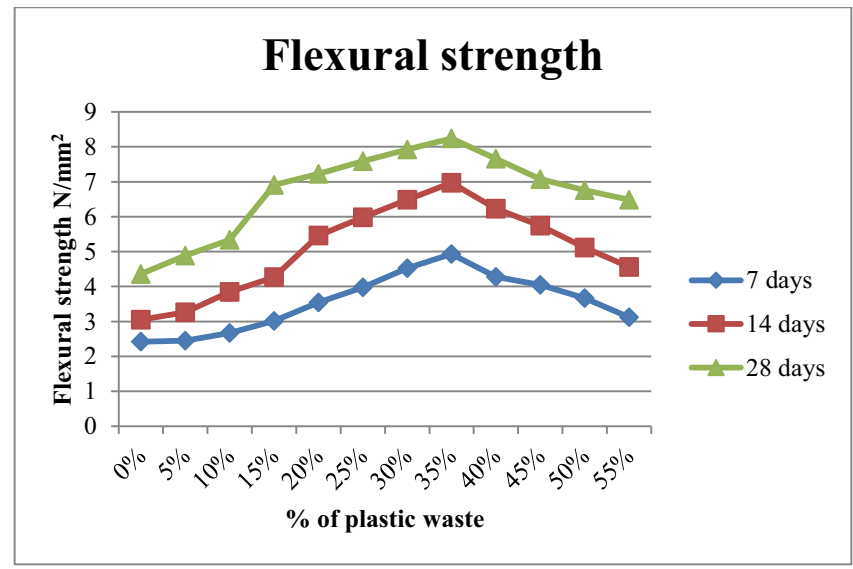

Fig. 7. Flexural strength of concrete with plastic waste aggregates at various ages

From the experimental results it is observed that there is a general trend of increase in compressive strength, split tensile strength and flexural strength of concrete upto the addition of $40 \%$ of glass aggregates and above this value upto $55 \%$ of the plastic aggregate replacements the strength values are comparable with the control mix.. 


\section{CONCLUSIONS}

From the experimental study on concrete with plastic Fine aggregates, the following observations are made,

Development in the mechanical properties of concrete are observed such as compressive strength, split tensile strength, thermal properties, energy absorption, flexural strength, crack arresting behavior etc. by adding post-consumer plastic wastes. However, a thorough investigation is required to be taken-up in this area.

According to the experimental results, it is observed that addition of plastic aggregate as fine aggregate replacements results in increase in compressive strength, split tensile strength and flexural strength upto $40 \%$ replacements for sand it is also found that upto $55 \%$ of sand replacements with plastic wastes, mechanical strength values are comparable with that of the normal concrete and hence they can be used in concrete productions in order to get both cost and environmental benefits. 


\section{REFERENCES}

1.Zainab Z. Ismail, Enas A. AL-Hashmi, Use of waste plastic in concrete mixture as aggregate replacement, Elsevier Waste Management 28 (2008) 2041-2047.

2.RafatSiddique, JamalKhatib, InderpreetKaur., Use of recycled plastic in concrete: A review, Volume 28, Issue 10, 2008, Pages 1835-1852.

3.O. YazoghliMarzouk, R.M.Dheilly, M.Queneudec., Valorization of post-consumer waste plastic in cementitious concrete composites, Volume 27, Issue 2, 2007, Pages 310 318.

4. A. A. Al-manaseer and T.r. Dalal, Concrete Containing Plastic Aggregates International Concrete Abstracts Portal-vol19, pp. 47-52.

5.NabajyotiSaikia,JorgedeBritoJorgedeBrito, Use of plastic waste as aggregate in cement mortar and concrete preparation: A review, Volume 34, September 2012, Pages 385-401.

6.Chien-Chung Chen, Nathan Jaffe, Matt Koppitz, Wesley Weimer, Albert, Concrete Mixture With Plastic As Fine Aggregate Replacement, International Journal of Advances in Mechanical and Civil Engineering, Volume-2, Issue-4, Aug.-2015,pp,49-53.

7.Kshiteesh Gaur , Jyotsana, Anil Kumar Arya, Neelesh Kumar Singh, Use of Plastic as Partial Replacement of Fine Aggregate in Fibre Reinforced Concrete, IOSR Journal of Mechanical and Civil Engineering, Volume 14, Issue 3 Ver. III (May. - June. 2017), PP 71-74.

8.B.Harini\&K.V.Ramana, Use of Recycled Plastic Waste as Partial Replacement for Fine Aggregate in Concrete, International Journal of Innovative Research in Science, Engineering and Technology, Vol. 4, Issue 9, September 2015, 8596-8603.

9.Neil N. Eldin, Member, Rubber- Tire Particles as Concrete Aggregate, Vol. 5, Issue 4 November 1993.

10.Amalu.R.G, Azeef Ashraf, Muhammad Hashim, Rejith.K.U, Vijitha.V., Use Of Waste Plastic As Fine Aggregate Substitute In Concrete, International Journal of Scientific \& Engineering Research, 172-177. 
11.Kettab R., Bali, A. and Alliche, E., Tire-modified sand concrete for waste management. International Journal of Nuclear Energy Science and Technology - Vol. 3, No. 1, 2007, pp. 63-75.

\section{LIST OF FIGURES AND TABLES:}

Fig.1. Polymer Industries Waste (PIW)

Fig.2. Bar chart for Compressive strength of concrete with plastic waste aggregates

Fig.3. Compressive strength of concrete with plastic waste aggregates at various ages

Fig.4. Bar chart for Split tensile strength of concrete with plastic waste aggregates

Fig.5. Chart for Split tensile strength of concrete with plastic waste aggregates at various ages

Fig.6. Bar chart for Flexural strength of concrete with plastic waste aggregates

Fig.7. Flexural strength of concrete with plastic waste aggregates at various ages

Tab.1. Compressive strength of concrete with plastic waste aggregates

Tab.2. Split tensile strength of concrete with plastic waste aggregates

Tab.3. Flexural strength of concrete with plastic waste aggregates 


\section{A PERFORMANCE STUdY ON PARTIAL REPLACEMENT OF POLYMER INDUSTRIES WASTE (PIW) AS FINE AGGREGATE IN CONCRETE}

KEYWORDS: polymer industrial waste (PIW), Compressive strength, Split Tensile, Flexure Fine aggregate (M-sand)

\section{SUMMARY:}

Polymer industrial final waste as fine aggregates of partial replacement in concrete. Researchers are focused exclusively on the production of fine aggregates as sustainable way. PIW fine aggregates have a better yield compared to normal river fine aggregates. Several scientists have conducted a study on replacement of natural fine aggregates with different wastes as fine aggregates. In the present study, PIW fine aggregates have been partially replaced by natural aggregates in the M30 concrete grade, in order to study mechanical and resilient properties. This shows that the PIW fine aggregate can be used for structural applications.This study was conducted for fresh and hardens concrete and we found the very good result. The paper focuses on the usefulness of PIW fine aggregates in concrete. Initially, PIW fine aggregates have been subjected to a physical examination, water content, water absorption, and the partial replacement of PIW aggregates for mixing with concrete. It was also intended to check the strength of PIW fine aggregates in concrete. Target compression strength of $30 \mathrm{~N} / \mathrm{mm} 2$ was developed and trial mixtures based on IS 10262: 2009 were obtained. According to the experimental results, it is observed that addition of plastic aggregate as fine aggregate replacements results in increase in compressive strength, split tensile strength and flexural strength upto $40 \%$ replacements for sand it is also found that upto $55 \%$ of sand replacements with plastic wastes, mechanical strength values are comparable with that of the normal concrete and hence they can be used in concrete productions in order to get both cost and environmental benefits. 